\title{
Evaluation of the sample needed to accurately estimate outcome-based measurements of dairy welfare on farm
}

\author{
M. I. Endres, ${ }^{* 1}$ K. M. Lobeck-Luchterhand, ${ }^{*}$ L. A. Espejo, $†$ and C. B. Tuckerł \\ *Department of Animal Science, and \\ †Department of Veterinary Population Medicine, University of Minnesota, St. Paul 55108 \\ ‡Department of Animal Science, University of California, Davis 95616
}

\section{ABSTRACT}

Dairy welfare assessment programs are becoming more common on US farms. Outcome-based measurements, such as locomotion, hock lesion, hygiene, and body condition scores (BCS), are included in these assessments. The objective of the current study was to investigate the proportion of cows in the pen or subsamples of pens on a farm needed to provide an accurate estimate of the previously mentioned measurements. In experiment 1 , we evaluated cows in 52 high pens ( 50 farms) for lameness using a 1- to 5-scale locomotion scoring system $(1=$ normal and $5=$ severely lame; 24.4 and $6 \%$ of animals were scored $\geq 3$ or $\geq 4$, respectively). Cows were also given a BCS using a 1- to 5-scale, where $1=$ emaciated and $5=$ obese; cows were rarely thin (BCS $\leq 2$; $0.10 \%$ of cows) or fat (BCS $\geq 4 ; 0.11 \%$ of cows). Hygiene scores were assessed on a 1 - to 5 -scale with $1=$ clean and $5=$ severely dirty; $54.9 \%$ of cows had a hygiene score $\geq 3$. Hock injuries were classified as $1=$ no lesion, $2=$ mild lesion, and $3=$ severe lesion; $10.6 \%$ of cows had a score of 3 . Subsets of data were created with 10 replicates of random sampling that represented 100, 90, $80,70,60,50,40,30,20,15,10,5$, and $3 \%$ of the cows measured/pen. In experiment 2 , we scored the same outcome measures on all cows in lactating pens from 12 farms and evaluated using pen subsamples: high; high and fresh; high, fresh, and hospital; and high, low, and hospital. For both experiments, the association between the estimates derived from all subsamples and entire pen (experiment 1) or herd (experiment 2) prevalence was evaluated using linear regression. To be considered a good estimate, 3 criteria must be met: $\mathrm{R}^{2}>0.9$, slope $=1$, and intercept $=0$. In experiment 1 , on average, recording $15 \%$ of the pen represented the percentage of clinically lame cows (score $\geq 3$ ), whereas $30 \%$ needed to be measured to estimate severe lameness (score $\geq 4$ ). Only $15 \%$ of the pen was needed to estimate the per-

Received September 6, 2013.

Accepted February 5, 2014.

${ }^{1}$ Corresponding author: miendres@umn.edu centage of the herd with a hygiene score $\geq 3$, whereas $30 \%$ to estimate the prevalence of severe hock lesions. Estimating very thin and fat cows required that 70 to $80 \%$ of the pen be measured. In experiment 2 , none of the pen subsamples met our criteria for accurate estimates of herd prevalence. In conclusion, we found that both a higher percentage of the pen must be sampled to generate accurate values for relatively rare parameters and that the population measured plays an important role in prevalence estimates.

Key words: dairy welfare assessment, sampling size, lameness

\section{INTRODUCTION}

Animal welfare assessments and audits are becoming more common in the dairy industry. Examples of these assessments include the National Dairy FARM Program (www.nationaldairyfarm.com) in the United States and the Welfare Quality Program (www.welfarequality.net) in Europe. Outcome- or animal-based measurements, such as locomotion, hock lesion, hygiene, and BCS, are included in these assessments. Obtaining these animal-based measures is essential to truly assess the animal welfare quality on each farm, as these measurements provide valuable information about how cows are responding to their environment. Webster (2005) summarized that an effective animal welfare assessment program must incorporate both measures of husbandry provision (e.g., resources and management) and welfare (he defined welfare as capacity to sustain fitness and avoid suffering).

Ideally, sampling regimens used in each assessment provide accurate prevalence information for the previously mentioned outcome-based measurements that can evaluate welfare. The traditional approach of using sample size calculation to estimate the herd-level prevalence in a finite population depends on the population size, expected prevalence, level of precision, and the confidence level of the estimation (Cannon and Roe, 1982; Dohoo et al., 2010). Therefore, this approach assumes knowledge of the approximate prevalence before 
sampling the cows, which may include high levels of uncertainty in field conditions. Relatively little is known about sampling required to ensure accuracy in animal welfare evaluations, as most previous studies have assessed the entire herd when evaluating (e.g., lameness prevalence; Huxley et al., 2004; Haskell et al., 2006). It is known, however, that scoring entire herds can be time and cost prohibitive, particularly on large farms.

Very limited research has been done on sampling methods for dairy welfare evaluation, especially in the United States, where $47 \%$ of herds have 500 or more lactating cows (USDA, 2008). Dairy welfare assessment programs calculate sample number of cows per pen based on the number of cows in the herd or pen (e.g., National Dairy FARM Program; Welfare Quality), whereas some industry professionals have suggested that perhaps a representative pen or subsamples of pens be used to estimate herd prevalence. Validation of these 2 approaches for all outcome-based measurements described has not been reported.

To date, 2 studies evaluating sampling methods for dairy cattle have focused on lameness. Main et al. (2010) investigated sampling strategies to monitor lameness in dairy cattle in 224 herds in the United Kingdom. They found that presence of more than 1 severely lame cow on a farm could be an indication of a herd lameness problem; for the 182 farms with at least 1 severely lame cow present, $80 \%$ of them had $>25 \%$ lameness prevalence. They also suggested that using a sampling strategy based on milking parlor exit order could provide an accurate estimate of true prevalence in the herd. For 36 herds that were larger than 100 cows, sampling a maximum of 100 cows from the middle of the milking order produced an estimate of prevalence within $5 \%$ of the true prevalence (their criteria for a good estimate) on $83 \%$ of farms. In larger herds, however, this would require the presence of the evaluator on the farm for about $8 \mathrm{~h}$ to score every pen (fresh, high, mid, and low production strings) in the middle of milking order. Though valuable, the largest farm in Main et al. (2010) had 268 cows, some farms had only 1 group of cows, and the relationship between true and estimated prevalence was not statistically compared with farm as the experimental unit. A second study by Hoffman et al. (2013) used 5 herds in the western United States. Herd size ranged from 148 to 2,744 cows. They found that estimates of lameness prevalence using both cows in the middle of milking parlor exit and a calculated sample across the herd were within $5 \%$ of true values. However, with only 5 herds in total, they did not have adequate power to assess the accuracy of these methods across farms (where dairy operation serves as the experimental unit). They also investigated locomotion scoring certain pens or combinations of pens. This would allow the assessor to schedule the visit at the time those pens are being milked, reducing the overall welfare assessment time. They concluded that pen-level prevalence was variable and not a good predictor of herd-level lameness prevalence, again based on being within 5\% of true values rather than a statistical comparison.

The objective of the present study was to statistically evaluate the proportion of cows in the high pen or subsamples of pens needed to provide an accurate estimate of locomotion, body condition, hygiene, and hock lesion scores.

\section{MATERIALS AND METHODS}

\section{Data Sets}

Two previously collected, on-farm data sets were used in the current study. In experiment 1 , data from 52 high group pens in 50 farms were used. Dairy farms for this data set had been selected randomly from the total population of herds having more than 150 cows situated within a geographical area where most of the dairy farms in Minnesota are located. All farms had Holstein cows as the predominant breed. No previous knowledge existed about prevalence of lameness, hock lesions, hygiene, or BCS in these farms. Farms had, on average, $474 \pm 321$ (mean $\pm \mathrm{SD}$ ) cows and milk production averaged $32.9 \pm 5.4 \mathrm{~kg}$ of FCM per cow per day. Group size averaged $117 \pm 51$ cows. A total of 5,626 cows were included in the data set. Sixteen of the 52 total groups in the data set were high-production groups, which did not include first-lactation cows. High-production cows (as defined by the herd manager) housed in the hospital pen during the visit also were included in the data set. Approximately $49 \%$ of the cows included in the data set were more than 150 DIM. Thirty percent of the pens had deep-sand freestalls and $70 \%$ had mattresses.

In experiment 2, data from 12 freestall dairy farms in Minnesota and southeast South Dakota were used. Dairy farms for this data set had Holstein as the primary breed and 2 herds had approximately 30\% JerseyHolstein crossbreds. All barns used deep-bedded sand stalls, and freestalls were similar in size and design across facilities, with an average width of approximately $122 \mathrm{~cm}$, length of $244 \mathrm{~cm}$, and neck rail height of 122 $\mathrm{cm}$. Farms were visited once each season for a total of 4 visits per farm. Visits during January and February were considered winter; April and May, spring; July and August, summer; and October and November, fall. The mean number of lactating animals on each farm ranged from 399 to 1,564, with an average of 913 cows per farm. Average production was $37.3 \pm 12.0 \mathrm{~kg}$ of FCM/cow per day. A total of 42,693 cows were scored across all farms and visits. 


\section{Animal Measurements}

On each visit, cows in the high group (experiment 1 ) or each lactating pen (experiment 2) were visually scored for locomotion, body condition, hygiene, and hock lesions. Cows were evaluated for lameness using a 1- to 5-scale locomotion scoring method (Flower and Weary, 2006) by 1 trained observer as they exited the milking parlor. Locomotion scores were identified as 1 $=$ normal locomotion, $2=$ imperfect locomotion, $3=$ lame, $4=$ moderately lame, and $5=$ severely lame. Cows were considered lame if their score was $\geq 3$ and severely lame if their score was $\geq 4$. Animals were scored for body condition using a 1- to 5-scale, where $1=$ emaciated and $5=$ obese (Ferguson et al. 1994), by another trained observer. For our study, cows were classified as thin $(\mathrm{BCS} \leq 2)$ or fat $(\mathrm{BCS} \geq 4)$. Hygiene scores were assessed by the amount of dirt on the udder and lower hind legs based on a 1- to 5-scale, with $1=$ clean and $5=$ severely dirty (Reneau et al., 2005). For the present study, cows were classified as dirty (score $3-5)$ or very dirty (score $4-5$ ). Hock lesions were classified as 1 = no lesion, $2=$ hair loss (mild lesion), $3=$ swollen hock with or without hair loss (severe lesion). Hygiene and hock lesion scores were collected in the parlor by a third trained observer.

\section{Statistical Analysis}

Experiment 1. Subsets of data from each farm were created with 10 iterations of random sampling with replacement using PROC SURVEY SELECT in SAS (version 9.2, SAS Institute Inc., Cary, NC). The rep statement $=10$ and farm were included in the strata statement. These subsets represented 100, 90, 80, 70, $60,50,40,30,20,15,10,5$, and $3 \%$ of the cows measured per farm. The association between the estimates derived from each subset and the estimated prevalence of the pens was evaluated using linear regression (PROC REG; SAS version 9.2). Prevalence was calculated for the common problems likely identified in an assessment: fat or thin cows, lameness, hock injury, and dirty cows. Three criteria were used to determine if the subset accurately represented the actual values: $\mathrm{R}^{2}$ $>0.9$, slope $=1$, and intercept $=0$. The latter 2 were tested statistically in PROC REG. This process was repeated for farms with more than 96 cows in the highproducing group $(\mathrm{n}=25)$ and all farms $(\mathrm{n}=52)$. We chose groups with $>96$ cows to represent larger pens and because a break-point in the distribution of group size was present at this point (Figure 1).

Experiment 2. Linear regression was used to compare farm prevalence to estimates based on subsamples

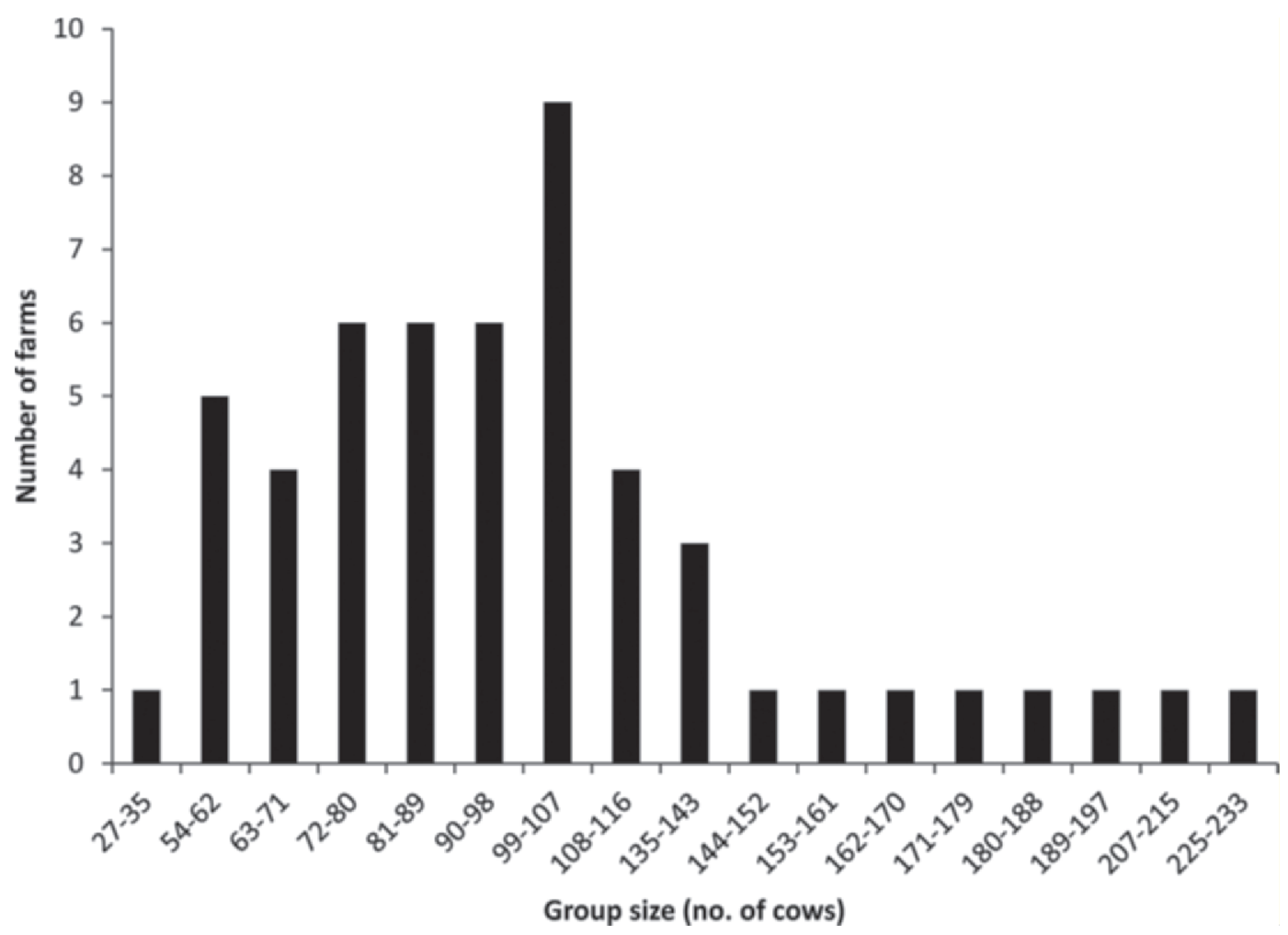

Figure 1. Frequency distribution of group size on 52 farms. For some analyses, farms were categorized by having $>96$ cows in the group (n $=25)$. 
Table 1. Average ( \pm SE) prevalence of lameness (locomotion score), hock injuries (hock injury score), hygiene (hygiene score), and extremes in body condition (BCS) on farms with 96 or more cows in the high-producing group $(\mathrm{n}=25)$ or all farms assessed $(\mathrm{n}=52$; highproducing groups of all sizes)

\begin{tabular}{lcr}
\hline Item & $\begin{array}{c}96 \text { or more cows } \\
(\mathrm{n}=25)\end{array}$ & $\begin{array}{c}\text { All farms } \\
(\mathrm{n}=52)\end{array}$ \\
\hline Locomotion score $\geq 3$ & $22.3 \pm 1.5$ & $24.4 \pm 1.6$ \\
Locomotion score $\geq 4$ & $5.3 \pm 0.6$ & $6.0 \pm 0.6$ \\
Hock score $\geq 2$ & $59.2 \pm 4.8$ & $58.6 \pm 3.8$ \\
Hock score 3 & $9.3 \pm 1.4$ & $10.6 \pm 1.4$ \\
Hygiene score $\geq 3$ & $55.5 \pm 3.5$ & $54.9 \pm 2.7$ \\
Hygiene score $\geq 4$ & $3.6 \pm 0.6$ & $4.3 \pm 0.8$ \\
BCS $\leq 2$ & $0.2 \pm 0.1$ & $0.1 \pm 0.1$ \\
BCS $\geq 4$ & $0.2 \pm 0.1$ & $0.1 \pm 0.1$ \\
\hline
\end{tabular}

from specific pens: high $(\mathrm{n}=12$ farms); high and fresh ( $\mathrm{n}=12$ farms); high, fresh, and hospital ( $\mathrm{n}=6$ farms); and high, low, and hospital ( $\mathrm{n}=6$ farms, smaller, as not all farms had hospital pens). These analyses were done separately for each season (fall, winter, spring, summer). As with experiment 1, 3 criteria were used to determine if the subsample accurately represented the herd-level prevalence: $\mathrm{R}^{2}>0.9$, slope $=1$, and intercept $=0$.

\section{RESULTS}

\section{Experiment 1}

Cows were rarely thin (BCS $\leq 2 ; 0.1 \pm 0.1$ ) or fat (BCS $\geq 4 ; 0.1 \pm 0.1$; Table 1$)$. A relatively large portion of the cows $(54.9 \pm 2.7)$ were dirty (hygiene score $\geq 3$ ). Across all farms, $24.4 \pm 1.6 \%$ of the cows were classified as lame (locomotion score $\geq 3$ ), and $6.0 \pm 0.6 \%$ were classified as severely lame (score $\geq 4$ ). In addition, $10.6 \pm 1.4 \%$ of cows had severe hock lesions (hock score
$=3$ ), whereas $58.6 \pm 3.8 \%$ had either a severe or mild hock lesion.

The subsample required to accurately represent the entire pen prevalence is reported in Table 2. It is reported in 2 ways: as the proportion sampled for all 10 iterations to meet the criteria for a good estimate $\left(\mathrm{R}^{2}\right.$ $>0.9$, slope $=1$, and intercept $=0$; most conservative approach), and as the proportion sampled for the average of the iterations to meet the criteria. Coefficients of determination $\left(\mathrm{R}^{2}\right)$ tended to decline as fewer cows were sampled (Figure 2), and this was particularly marked for very rare parameters, such as extremes in body condition. Indeed, it is doubtful whether this regression approach is appropriate for these very rare extremes in body condition. To illustrate this point, the relationships between average estimates from subsampling are compared with actual values in Figure 3.

\section{Experiment 2}

Prevalence for lameness, hygiene, and hock scores, as well as BCS, are reported in Table 3 for the entire herd and subsamples from 4 pens: high only; high and fresh; high, fresh, and hospital; and high, low, and hospital. None of these pen subsamples met our criteria for accurate estimate of the entire herd (i.e., $\mathrm{R}^{2}>$ 0.9 , slope and intercept statistically equal to 1 and 0 , respectively). The coefficient of determination varied with outcome measure and pen sampled (Table 4), with some approaching 0.9 , but $71 \%$ of all comparisons had slopes that were statistically different from 1.

\section{DISCUSSION}

With the data set used in our study and the approach of the proportion of the herd that needed to be

Table 2. The proportion of high-producing dairy cows that would need to be sampled to estimate lameness, hock injuries, hygiene, and extremes in body condition ${ }^{1}$

\begin{tabular}{|c|c|c|c|c|}
\hline \multirow[b]{2}{*}{ Item } & \multicolumn{2}{|c|}{$\begin{array}{c}\text { Proportion where all } \\
10 \text { iterations met criteria }\end{array}$} & \multicolumn{2}{|c|}{$\begin{array}{l}\text { Proportion where the average } \\
\text { of iterations met criteria }\end{array}$} \\
\hline & $\begin{array}{l}96 \text { or more cows } \\
(\mathrm{n}=25)\end{array}$ & $\begin{array}{l}\text { All farms } \\
(\mathrm{n}=52)\end{array}$ & $\begin{array}{l}96 \text { or more cows } \\
(\mathrm{n}=25)\end{array}$ & $\begin{array}{l}\text { All farms } \\
(\mathrm{n}=52)\end{array}$ \\
\hline Locomotion score $\geq 3$ & 0.30 & 0.20 & 0.15 & 0.15 \\
\hline Locomotion score $\geq 4$ & 0.40 & 0.40 & 0.40 & 0.30 \\
\hline Hock score $\geq 2$ & 0.15 & 0.30 & 0.15 & 0.15 \\
\hline Hock score $\overline{3}$ & 0.40 & 0.70 & 0.30 & 0.30 \\
\hline Hygiene score $\geq 3$ & 0.30 & 0.30 & 0.10 & 0.15 \\
\hline Hygiene score $\geq 4$ & 0.50 & 1.00 & 0.50 & 0.30 \\
\hline $\mathrm{BCS} \leq 2$ & 1.00 & 1.00 & 1.00 & 0.80 \\
\hline $\mathrm{BCS} \geq 4$ & 1.00 & 1.00 & 0.70 & 0.80 \\
\hline
\end{tabular}

${ }^{1}$ Percentages are determined based on the relationship with true values (criteria: $\mathrm{R}^{2}>0.9$; slope and intercept are not different from 1 and 0 , respectively) from farms with 96 or more cows in the high-producing group (n $=25)$ or all farms assessed $(\mathrm{n}=52$; high-producing groups of all sizes). Relationships with true values were calculated with random sampling [10 iterations; either the proportion where all 10 iterations met criteria (more conservative approach) or the proportion sampled for the average of the iterations to meet the criteria]. 

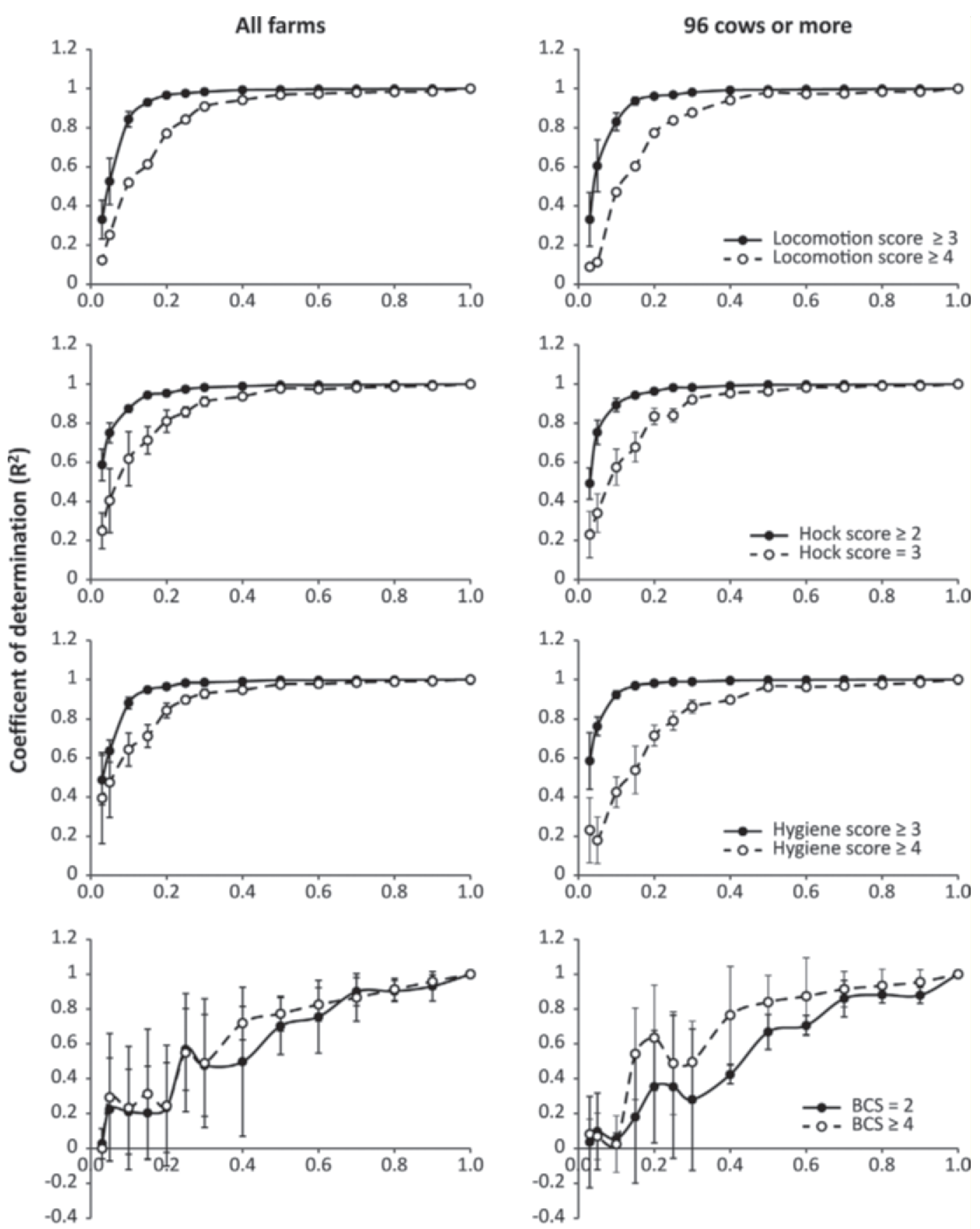

Proportion of herd sampled

Figure 2. Average coefficient of determination for relationship between true values and estimates based on 10 random iterations of a subset from all farms ( $\mathrm{n}=52$; high-producing groups of all sizes) or farms with $>96$ cows in high-producing groups $(\mathrm{n}=25)$. Lameness, hock injuries, hygiene, and extremes in body condition were assessed. Error bars represent SD.

sampled for the average of the iterations to meet the criteria, recording $15 \%$ of the animals accurately represented the percentage of clinically lame cows (score $\geq 3$ ), whereas $30 \%$ needed to be measured to estimate severe lameness (score $\geq 4$ ) when all farms were included. In addition, scoring only $15 \%$ of the animals was needed to estimate the percentage of the herd with hygiene score $\geq 3$, whereas $30 \%$ was needed to estimate the prevalence of severe hock lesions. To generate accurate prevalence, more animals needed to be measured when 

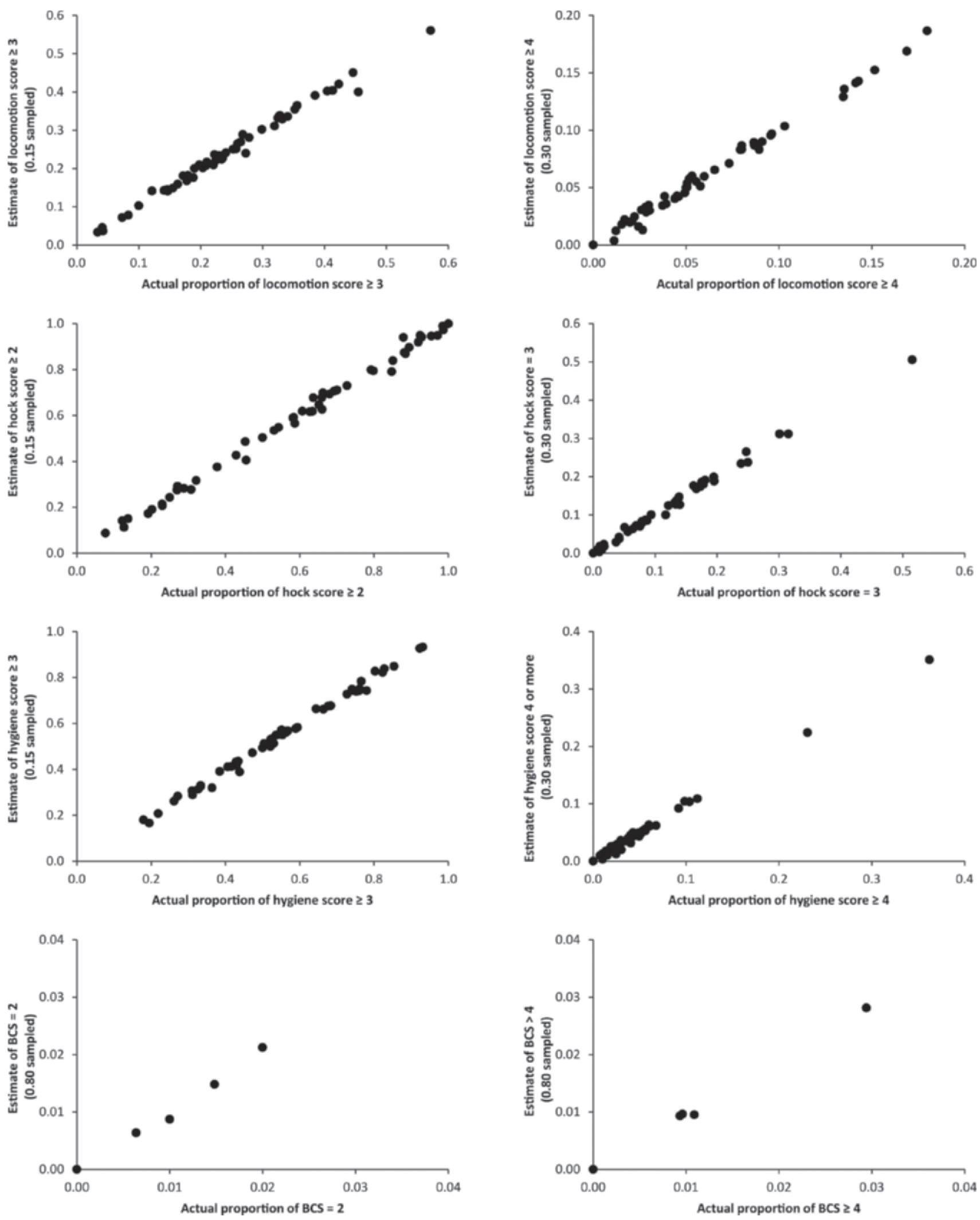

Figure 3. Relationship between actual proportion of lameness (locomotion score), hock injuries (hock score), cleanliness (hygiene score), extremes in body condition, and the estimate generated by sampling the cut-off value identified with the average iterations meeting the criteria (Table 2; also given in $\mathrm{y}$-axis label). Values for all farms $(\mathrm{n}=52$; high-producing groups of all sizes $)$ are shown. 
Table 3. Mean ( \pm SE) prevalence across seasons of lameness (locomotion score), hock injuries (hock injury score), hygiene (hygiene score), and extremes in body condition (BCS) on farms where all cows had been assessed

\begin{tabular}{lrcccc}
\hline Item & \multicolumn{1}{c}{$\begin{array}{c}\text { Entire } \\
\text { herd }\end{array}$} & $\begin{array}{c}\text { High } \\
(\mathrm{n}=12)\end{array}$ & $\begin{array}{c}\text { High and fresh } \\
(\mathrm{n}=12)\end{array}$ & $\begin{array}{c}\text { High, fresh, and } \\
\text { hospital }(\mathrm{n}=6)\end{array}$ & $\begin{array}{c}\text { High, low, and } \\
\text { hospital }(\mathrm{n}=6)\end{array}$ \\
\hline Locomotion score $\geq 3$ & $17.1 \pm 1.0$ & $17.6 \pm 1.3$ & $17.7 \pm 1.2$ & $23.2 \pm 1.4$ & $25.3 \pm 1.8$ \\
Locomotion score $\geq 4$ & $2.9 \pm 0.4$ & $2.9 \pm 0.4$ & $3 \pm 0.4$ & $4.9 \pm 0.6$ & $5.1 \pm 0.8$ \\
Hock score $\geq 2$ & $33.4 \pm 2.1$ & $32.8 \pm 1.8$ & $30.5 \pm 1.9$ & $32.6 \pm 2.7$ & $39.1 \pm 3.5$ \\
Hock score 3 & $9.5 \pm 0.8$ & $9 \pm 0.7$ & $8.4 \pm 0.7$ & $10.5 \pm 1.2$ & $13.8 \pm 1.7$ \\
Hygiene score $\geq 3$ & $44.3 \pm 2.6$ & $50.6 \pm 3$ & $53 \pm 2.8$ & $49.9 \pm 4.5$ & $41.6 \pm 3.8$ \\
Hygiene score $\geq 4$ & $5.5 \pm 0.7$ & $4.7 \pm 0.8$ & $7.8 \pm 1.3$ & $8.5 \pm 1.9$ & $4.9 \pm 1$ \\
BCS $\leq 2$ & $0.3 \pm 0.1$ & $0.4 \pm 0.1$ & $0.4 \pm 0.1$ & $0.3 \pm 0.1$ & $0.2 \pm 0.1$ \\
BCS $\geq 4$ & $1.5 \pm 0.2$ & $0.7 \pm 0.1$ & $0.7 \pm 0.2$ & $0.8 \pm 0.2$ & $1.9 \pm 0.4$ \\
\hline
\end{tabular}

${ }^{1}$ Values are presented for the entire herd and 4 subsets: high; high and fresh; high, fresh, and hospital; and high, low, and hospital pens

we used fewer farms (e.g., only those with more than 96 cows) or when criteria were more stringent (all iterations meeting criteria). In all scenarios, rare problems, such as fat or thin cows, required that much more of the herd be measured to detect these concerns. Indeed, sampling would likely need to be different when a certain category is less frequent than it was in the current study. This could easily be the case for hock injuries, for example, which are less common in regions such as California, compared with the northeast (von Keyerslingk et al., 2012). Therefore, caution is needed when determining sampling methods at different prevalences for the various outcome-based measurements used to assess dairy welfare on farms.

One of the goals of our investigation was to learn whether a representative sample or certain pens could be scored for the various measurements investigated to result in an accurate estimate. The high, low, and hospital pen were added to our analysis after work presented by Hoffman et al. (2013). Those authors indicated that hoof health representatives have suggested sampling a high-production, a low-production, and hospital pen to estimate herd lameness prevalence. Our choice of high and a combination of high and fresh or high, fresh, and hospital, was based on common milking schedules on large dairy farms, such that the dairy welfare evaluator could schedule the visit for the time the fresh, followed by the high group are being milked, then go to the hospital pen (usually a small group) to score those cows. Based on our relatively small sample size of 12 farms, it appears that only scoring certain pens will not result in an accurate estimate based on the criteria used in our study. This result agrees with Hoffman et al. (2013), who indicated that too much variability exists in penlevel lameness prevalence; however, their study also had a relatively small sample ( $\mathrm{n}=5$ farms). Other parameters measured in our study (body condition, hygiene, and hock lesions) could not be measured accurately by using pen subsamples either.

We expect that newly developed automated methods to estimate lameness (Chapinal et al., 2010, 2011) would help reduce the subjectivity of lameness assessment on dairy farms and be helpful in providing more accurate dairy welfare assessments. However, these technologies need to become affordable for dairy producers. Some efforts have also been undertaken to score body condition of dairy cows automatically (Azzaro et al., 2011); however, it would be more difficult

Table 4. Average coefficient of determination $\left(R^{2}\right)$ across seasons between true prevalence and estimated prevalence of lameness (locomotion score), hock injuries (hock injury score), hygiene (hygiene score), and extremes in body condition ${ }^{1}$

\begin{tabular}{lcccc}
\hline Measurement & $\begin{array}{c}\text { High } \\
(\mathrm{n}=12)\end{array}$ & $\begin{array}{c}\text { High and fresh } \\
(\mathrm{n}=12)\end{array}$ & $\begin{array}{c}\text { High, fresh, and } \\
\text { hospital }(\mathrm{n}=6)\end{array}$ & $\begin{array}{c}\text { High, low, and } \\
\text { hospital }(\mathrm{n}=6)\end{array}$ \\
\hline Locomotion score $\geq 3$ & 0.65 & 0.79 & 0.77 & 0.83 \\
Locomotion score $\geq 4$ & 0.52 & 0.73 & 0.78 & 0.87 \\
Hock score $\geq 2$ & 0.71 & 0.76 & 0.80 & 0.90 \\
Hock score 3 & 0.67 & 0.71 & 0.88 & 0.92 \\
Hygiene score $\geq 3$ & 0.61 & 0.69 & 0.73 & 0.85 \\
Hygiene score $\geq 4$ & 0.38 & 0.66 & 0.69 & 0.84 \\
BCS $\leq 2$ & 0.26 & 0.34 & 0.57 & 0.59 \\
BCS $\geq 4$ & 0.39 & 0.37 & & 0.46 \\
\hline
\end{tabular}

${ }^{1}$ Estimated prevalence is based on subsampling only the high; high and fresh; high, fresh, and hospital; and high, low, and hospital pens on 12 freestall farms in Minnesota and South Dakota. 
to assess hygiene and hock lesion prevalence using current technology.

\section{CONCLUSIONS}

In the first study to statistically compare sampling of outcome-based measures of dairy welfare, we found that more common problems require that fewer animals be measured to generate accurate prevalence estimates. Currently, on dairies in Minnesota, many cows would need to be sampled to generate accurate information for extremes in body condition, but fewer are needed to estimate more common problems such as lameness, hock injuries, and dirtiness.

\section{REFERENCES}

Azzaro, G., M. Caccamo, J. D. Ferguson, S. Battiato, G. M. Farinella, G. C. Guarnera, G. Puglisi, R. Petriglieri, and G. Licitra. 2011. Objective estimation of body condition score by modeling cow body shape from digital images. J. Dairy Sci. 94:2126-2137.

Cannon, R. M., and R. T. Roe. 1982. Livestock Disease Surveys. A Field Manual for Veterinarians. Bureau of Rural Science, Department of Primary Industry. Australian Government Publishing Service, Canberra.

Chapinal, N., A. M. de Passillé, M. Pastell, L. Hanninen, L. Munksgaard, and J. Rushen. 2011. Measurement of acceleration while walking as an automated method for gait assessment in dairy cattle. J. Dairy Sci. 94:2895-2901.

Chapinal, N., A. M. de Passillé, J. Rushen, and S. Wagner. 2010. Automated methods for detecting lameness and measuring analgesia in dairy cattle. J. Dairy Sci. 93:2007-2013.
Dohoo, I. R., W. Martin, and H. Stryhn. 2010. Veterinary Epidemiologic Research. 2nd ed. Atlantic Veterinary College Inc., University of Prince Edward Island, Charlottetown, Canada.

Ferguson, J. D., D. T. Galligan, and N. Thomsen. 1994. Principal descriptors of body condition score in Holstein cows. J. Dairy Sci. 77:2695-2703.

Flower, F. C., and D. M. Weary. 2006. Effect of hoof pathologies on subjective assessments of dairy cow gait. J. Dairy Sci. 89:139-146.

Haskell, M. J., L. J. Rennie, V. A. Bowell, M. J. Bell, and A. B. Lawrence. 2006. Housing system, milk production, and zerograzing effects on lameness and leg injury in dairy cows. J. Dairy Sci 89:4259-4266.

Hoffman, A. C., D. A. Moore, J. R. Wenz, and J. Vanegas. 2013 Comparison of modeled sampling strategies for estimation of dairy herd lameness prevalence and cow-level variables associated with lameness. J. Dairy Sci. 96:5746-5755.

Huxley, J. N., J. Burke, S. Roderick, D. C. J. Main, and H. R. Whay. 2004. Animal welfare assessment benchmarking as a tool for health and welfare planning in organic dairy herds. Vet. Rec. 155:237239.

Main, D. C. J., Z. E. Barker, K. A. Leach, N. J. Bell, H. R. Whay, and W. J. Browne. 2010. Sampling strategies for monitoring lameness in dairy cattle. J. Dairy Sci. 93:1970-1978.

Reneau, J. K., A. J. Seykora, B. J. Heins, M. I. Endres, R. J. Farnsworth, and R. Bey. 2005. Association between hygiene scores and somatic cell scores in dairy cattle. J. Am. Vet. Med. Assoc. 227:1297-1301.

USDA. 2008. Dairy 2007, Part II: Changes in the U.S. Dairy Cattle Industry, 1991-2007. USDA, Animal and Plant Health Inspection Service, Veterinary Service, Centers for Epidemiology and Animal Health (CEAH), Fort Collins, CO.

von Keyserlingk, M. A., A. Barrientos, K. Ito, E. Galo, and D. M. Weary. 2012. Benchmarking cow comfort on North American freestall dairies: Lameness, leg injuries, lying time, facility design, and management for high-producing Holstein dairy cows. J. Dairy Sci. 95:7399-7408.

Webster, J. 2005. The assessment and implementation of animal welfare: Theory into practice. Rev. Sci. Tech. 24:723-734 